\title{
ANALYSES OF MONTHLY DISCHARGES IN SLOVAKIA USING HYDROLOGICAL EXPLORATORY METHODS AND STATISTICAL METHODS
}

\author{
Mária ĎURIGOVÁ ${ }^{1 *}$, Dominika, BALLOVÁ ${ }^{2}$ Kamila HLAVČOVÁ ${ }^{1}$
}

\section{Abstract}

Detailed analyses of hydrological data are necessary in order to examine changes in their character. This article focuses on an analysis of the average monthly discharges of 14 stage-discharge gauging stations in Slovakia. The measured period is from 1931 to 2016. The approaches used are hydrological exploration methods, which were created by hydrologists to describe the behaviour of hydrological time series. The methods are used to identify a change-point through an analysis of any residuals, Pettitt's test, and an analysis of the relationship between the mean annual discharge deviations from the long-term annual discharge and the deviations of the average monthly discharge from the long-term average monthly discharge. A considerable number of change-points were identified in the 1970s and 1980 s. The results of the analyses show changes in the hydrological regimes, but to confirm the accuracy of the outcomes, it is also necessary to examine other hydrological and meteorological elements such as, e.g., precipitation and the air temperature.

\section{Address}

1 Dept. of Land and Water Resources Management, Slovak University of Technology, Bratislava, Slovakia

2 Dept. of Mathematics and Descriptive Geometry, Slovak University of Technology, Bratislava, Slovakia

* Corresponding author: maria.durigova@stuba.sk

\section{Key words}

- Monthly discharge,

- Hydrological exploratory methods,

- Change-point.

\section{INTRODUCTION}

Changes in natural phenomena, such as increasing sea levels, global warming, and more occurrences of extremes in hydrology and meteorology affect us and the environment. Studies directed at changes in hydrological regimes are of great importance, especially in the fields of water resources management, flood protection and the revitalization of rivers; they concentrate, e.g., on maintaining the quality of aquatic habitats or minimum discharges in the summer season (Barnett et al., 2005; Hlavčová et al., 2008; Škvarenina et al., 2010). The article is focused on mean monthly discharge analysis of 14 stage-discharge gauging stations in Slovakia measured from 1931 to 2016.

Identification of a change-point is a widely-used method to find the most probable location of an abrupt change in a time data series. The methods for detecting a change-point in hydroclimatic data include the standard normal homogeneity test, Wilcoxon's nonparametric test, two-phase regression procedures, an inhomogeneity test, and information criteria procedures and variations (Reeves et al., 2007). The number of methods offered different approaches to find location of the abrupt change in time data series. The comparative study (Lee et al., 2016) show the results of the three change-point detection methods, i.e. Cumulative Sum (CUSUM) method, Bayesian Change Point (BCP) method, and segmentation by Dynamic Programming (DP). The methods were applied to the synthetic rainfall data at the five station in South Korea. The best detection skill show BCP method with 0.9 posterior probability, and DP method could be reasonably recommended.

Gao et al., 2010 attempted to identify trends, change-points, and transition years in decreasing trends using Pettitt's test at 4 catchment areas in the Yellow River basin from 1950 to 2005. The change point for streamflow and sediment discharges was identified in 1985 for the Toudaoguai and Lijin catchment areas. For the Gongshui River basin, which was afflicted by soil erosion, Guo et al. 2018 used the daily precipitation, discharges, and sediment concentration to investigate trends and change-points. Pettitt's test of sediment discharges at seven stations showed significance $(\mathrm{P}=0.01$ and $\mathrm{P}=0.05)$, and various transition years were found. 
The detection of hydroclimatic changes in southwestern Louisiana rivers (Xue et al., 2018) showed change-points (detected by Pettitt's test) around the year 2004 for precipitation, soil moisture, water surplus, and streamflow, the year 1997 for the temperature, and the year 2000 for evapotranspiration. Sagarika et al. 2014 detected trends and change-points in 240 unimpaired streamflow stations for seasonal discharges. Pettitt's test identified significant change-points during the early 1970s and late 1980s. Xiong and Guo 2004 detected trends and change-points in the Yangtze River from 1882 to 2001 by a Bayesian approach. The annual minimum flow series had a change-point in 1934; the most probable location of a change-point for the annual mean discharge series was in the year 1968. The change-points for both the annual minimum and the annual mean series occurred before 1993

Villarini et al. 2011 examined temporal nonstationarities in the flood peak record, i.e. annual and seasonal maximum daily discharge time series. The investigated area include 55 stations in central Europe with a record of at least 75 years. Change-points in the mean and variance of the flood peak distributions were examined using the Pettitt test, the presence of monotonic patterns was examined by means of Spearman and Mann-Kendall tests. The largest frequencies of the maximal discharges were during winter in western part, during spring in eastern part, and during summer in southern part in investigated area. The statistical significant changes were not detected.

The application of rudimentary mean-shift change-point tests to scenarios with trends brings incorrect identifying changes. Gallagher et al. 2013 offers some simple homogeneity tests for time data series with application for temperature records in the continental United States and a local record from Jacksonville in Illinois.

The article focuses on detecting changes in average monthly discharges by using two hydrological exploratory methods and Pettitt's test. The aim of the article is to identify change-points and analyze the changes in a runoff regime. The analyses examine a long time series, i.e. period 1931-2016 for selected 14 stage-discharge gauging stations in Slovakia.

\section{MATERIALS AND METHODS}

Slovakia belongs to the north temperate climate zone. The mean annual temperature is from $6^{\circ} \mathrm{C}$ to $11^{\circ} \mathrm{C}$, and the mean annual rainfall total is from $500 \mathrm{~mm}$ to $2,000 \mathrm{~mm}$ (Implementation, 2007). The data series used are the mean monthly discharges of 14 stage-discharge gauging stations in Slovakia (Fig. 1, Tab. 1); all of them were measured from 1931 to 2016. The data was provided by the Slovak Hydrometeorological Institute.

The Morava River at Moravský Sv. Ján station has the biggest catchment area from selected rivers. There are rivers with catchment areas mainly from about $1,000 \mathrm{~km}^{2}$ to $3,800 \mathrm{~km}^{2}$, i.e., Orava, Kysuca, Hron, Slaná, Torysa, Topl'a and Poprad River. Then there are smaller catchments less than $1,000 \mathrm{~km}^{2}$, i.e., the Čierny Váh, Belá, Turiec, Ipel' and Hnilec River.

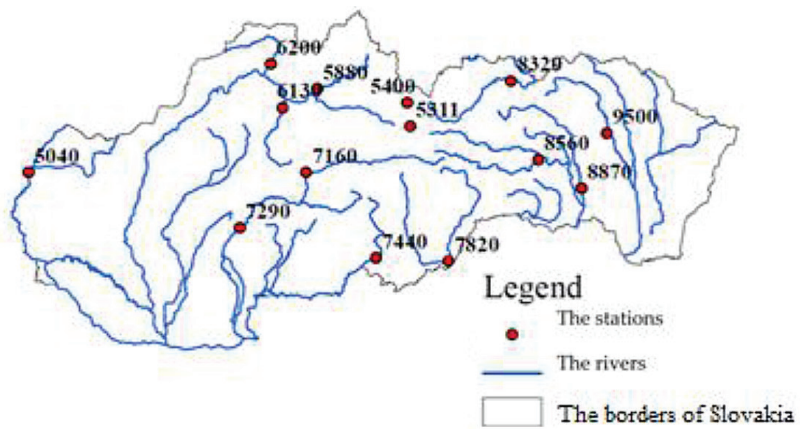

Fig. 1 The localization of the 14 stage-discharge gauging stations used in Slovakia
Tab. 1 List of the stage-discharge gauging stations with their numbering and the catchment areas

\begin{tabular}{|c|c|c|c|}
\hline $\begin{array}{l}\text { Stage-discharge } \\
\text { gauging stations }\end{array}$ & The rivers & $\begin{array}{c}\text { Number of } \\
\text { station }\end{array}$ & $\begin{array}{c}\text { Catchment area } \\
\left(\mathbf{k m}^{2}\right)\end{array}$ \\
\hline Moravský Sv. Ján & Morava & 5040 & $24,129.30$ \\
\hline Čierny Váh & Čierny Váh & 5311 & 243.06 \\
\hline Podbanské & Belá & 5400 & 93.49 \\
\hline Dierová & Orava & 5880 & $1,966.75$ \\
\hline Martin & Turiec & 6130 & 827.00 \\
\hline Kysucké Nové Mesto & Kysuca & 6200 & 955.09 \\
\hline Banská Bystrica & Hron & 7160 & $1,766.48$ \\
\hline Brehy & Hron & 7290 & $3,821.38$ \\
\hline Holiša & Ipel' & 7440 & 685.27 \\
\hline Lenártovce & Slaná & 7820 & $1,829.65$ \\
\hline Jaklovce & Hnilec & 8560 & 606.32 \\
\hline Košické Olšany & Torysa & 8870 & $1,298.30$ \\
\hline Hanušovce & Topl'a & 9500 & $1,050.03$ \\
\hline Chmelnica & Poprad & 8320 & $1,262.41$ \\
\hline
\end{tabular}

The mean basin elevation of the Morava River is $400.68 \mathrm{~m}$ a. s. 1 . The catchment of the Poprad River and upper Váh (Čierny Váh, Belá and Orava River) have maximum elevations about $1,500 \mathrm{~m}$ a. $\mathrm{s}$. 1 . The mean basin elevation of the Turiec River is $733.07 \mathrm{~m}$ a. s. 1. The mean basin elevation of the Kysuca River is 649.73 m a. s. 1. The mean basin elevation of the Hron River at Banská Bystrica station is 1,143.49 m a. s. 1. and the mean basin elevation of the Hron River at Brehy station is $669.53 \mathrm{~m}$ a. s. 1. The mean basin elevation of the Ipel' River and Slaná River have maximum elevation about 1,000 m a.s.l. (Jeneiová et. all, 2016).

Two methods were used to identify the change-points, i.e., an analysis of any residuals and Pettitt's test.

The analysis of the residuals consisted of calculating the residuals. They were calculated as the differences between the mean monthly discharges and the long-term mean monthly discharge. These residuals are cumulatively added and are then are plotted on a graph. The maximal value of the cumulative curve of the residuals represents the change-point.

Pettitt's test belongs to a group of nonparametric homogeneity tests. These tests allow researchers to determine if a series can be considered as homogeneous over time or if abrupt changes have appeared over time. This test seeks to find abrupt changes in the mean of series based on the ranking of the observations. It is a widely-used tool for detecting change-points in hydrological processes. The null hypothesis of this test is that there is no change in the mean of the time series. The alternative hypothesis says that there is a statistically significant change in the series. The test statistic is defined as:

$$
\widehat{U}=\max \left|U_{k}\right|
$$

where $U_{k}$ is given as:

$$
U_{k}=2 \sum_{i=1}^{k} r_{i}-k(n+1)
$$

where $k=1,2, \ldots, n$, and $r_{i}$ are the ranks of the observations $X i$. The most probable change-point is located where Û reaches its maximum value (Pettitt, 1979). 
Pettitt's test was evaluated with RStudio statistical software and used package was a trend. It obtained the most probable location of the change-point, and the significance of this change-point was evaluated by the corresponding p-value. If the p-value was less than the significance level of the test, we rejected the null hypothesis. That means there was a statistically significant change in the series. Otherwise, there was no statistically significant change-point in the series at the significance level selected.

The third method for analyzing changes in a runoff regime is based on an analysis of the relationship between the mean annual discharge deviations from the long-term annual discharges and the mean monthly discharge deviations from the long-term average monthly discharge. This method deals with the dependence of the runoff regime of each month on the runoff regime of that year. The method compares data time series divided into two periods. The mean annual discharge deviations obtained by considering the long-term mean annual discharge (Formula 3) and the mean monthly discharge obtained by deviations considering the long-term mean monthly discharge (Formula 4) were calculated. The deviations were calculated according to the formulas:

$$
\begin{aligned}
& \Delta_{1}=\frac{Q_{i}-Q}{Q} * 100 \\
& \Delta_{2}=\frac{Q_{j}-Q_{j}}{Q_{j}} * 100
\end{aligned}
$$

where:

$\Delta_{1}-$ the deviations of the mean annual discharges from the longterm mean annual discharge,

$Q_{i}$ - the mean annual discharge for each i-year,

$\bar{Q}$ - the long-term mean annual discharge,

$\Delta_{2}$ - the deviations of the mean monthly discharges from the long-term mean monthly discharge,

$Q_{j}$ - the mean monthly discharge of the j-month in that i-year,

$\bar{Q}_{j}-$ the long-term mean monthly discharge of the j-month.
The trend lines which were provided for the two periods look like a closed pair of scissors (Fig. 2). The more open the scissors, the greater the changes in the runoff regime of the specific month. The scissors created form an angle $\alpha$. The angle $\alpha$ ranges from $\left(10^{\circ},-10^{\circ}\right)$ to $\left(20^{\circ},-20^{\circ}\right)$ and indicates a certain change; an angle greater than $\left(20^{\circ},-20^{\circ}\right)$ indicates a significant change in the runoff regime (Tegelhoffová, 2013).

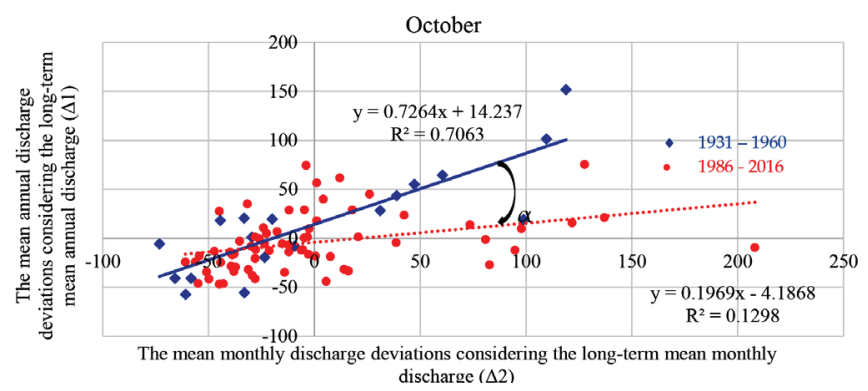

Fig. 2 A sample of the analysis of the changes in the runoff regime by the deviations

In order to apply this method, it is necessary to determine the method of dividing the time series into two periods. Four approaches were used to divide the time data series:

- A division of the time data series into two 30-year periods (Tab. 2, column 30-year per.). The first period was from 1931 to 1960 , and the second period was from 1986 to 2016 .

- A division of the time data series into two halves (Tab. 2, column 2 halves); the first period was from 1931 to 1973, and the second period was from 1974 to 2016.

- A division of the time data series by an analysis of the residuals. The change-point of the summer and winter periods (Tab. 3 , the columns $Q_{\text {sum }}$ and $Q_{\text {win }}$ ) determines the division of the time data series (Tab. 2, column CH-P of $Q_{\text {sum }}$ and column

\begin{tabular}{|c|c|c|c|c|c|c|c|c|c|c|}
\hline \multirow{2}{*}{ Station } & \multicolumn{2}{|c|}{ 30-year period } & \multicolumn{2}{|c|}{2 halves } & \multicolumn{2}{|c|}{ CH-P of $Q_{\text {sum }}$} & \multicolumn{2}{|c|}{ CH-P of $Q_{\text {win }}$} & \multicolumn{2}{|c|}{ CH-P of $Q_{m}$} \\
\hline & 1.per. & 2.per. & 1.per. & 2.per. & 1.per. & 2.per. & 1.per. & 2.per. & 1.per. & 2.per. \\
\hline 5040 & \multirow{14}{*}{$\begin{array}{l}\stackrel{8}{\circ} \\
\frac{1}{2} \\
\approx\end{array}$} & \multirow{14}{*}{$\begin{array}{l}0 \\
\stackrel{0}{0} \\
\text { 1े } \\
\dot{b} \\
\stackrel{2}{=}\end{array}$} & \multirow{14}{*}{ 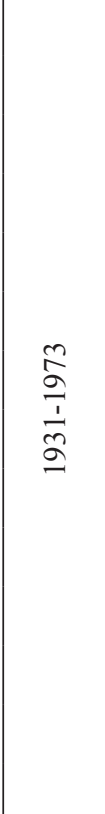 } & \multirow{14}{*}{ 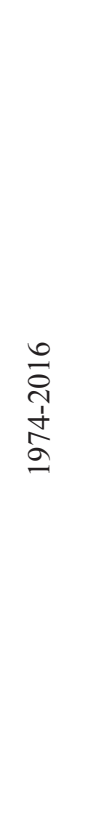 } & $1931-1942$ & $1943-2016$ & 1931-1948 & $1949-2016$ & $1931-1948$ & $1949-2016$ \\
\hline 5311 & & & & & 1931-1979 & $1980-2016$ & $1931-1983$ & $1984-2016$ & $1931-1980$ & $1981-2016$ \\
\hline 5400 & & & & & 1931-1964 & $1965-2016$ & $1931-1953$ & $1954-2016$ & 1931-1981 & $1982-2016$ \\
\hline 8880 & & & & & $1931-1945$ & $1946-2016$ & $1931-1983$ & $1984-2016$ & 1931-1949 & $1950-2016$ \\
\hline 6130 & & & & & 1931-1966 & $1967-2016$ & $1931-1977$ & $1978-2016$ & $1931-1967$ & $1968-2016$ \\
\hline 6200 & & & & & 1931-1987 & $1988-2016$ & $1931-1964$ & $1965-2016$ & $1931-2002$ & 2003-2016 \\
\hline 7160 & & & & & 1931-1985 & $1986-2016$ & 1931-1971 & $1972-2016$ & 1931-1981 & $1982-2016$ \\
\hline 7290 & & & & & 1931-1985 & $1986-2016$ & 1931-1981 & $1982-2016$ & 1931-1981 & $1982-2016$ \\
\hline 7440 & & & & & 1931-2009 & 2010-2016 & $1931-1981$ & $1982-2016$ & $1931-1981$ & $1982-2016$ \\
\hline 7820 & & & & & $1931-1953$ & $1954-2016$ & $1931-1983$ & $1984-2016$ & $1931-1980$ & $1981-2016$ \\
\hline 8560 & & & & & 1931-1955 & $1956-2016$ & $1931-1953$ & $1954-2016$ & $1931-1955$ & $1956-2016$ \\
\hline 8870 & & & & & 1931-1969 & $1970-2016$ & $1931-1983$ & 1984-2016 & $1931-1945$ & $1946-2016$ \\
\hline 9500 & & & & & 1931-1969 & $1970-2016$ & $1931-1983$ & $1984-2016$ & 1931-1981 & $1982-2016$ \\
\hline 8320 & & & & & 1931-1949 & $1950-2016$ & 1931-1971 & $1972-2016$ & 1931-1949 & $1950-2016$ \\
\hline
\end{tabular}

Tab. 2 Four approaches were used to divide the time data series into two periods 
CH-P of $Q_{\text {win }}$ ). The summer period was defined as from May to October and the winter period from November to April.

- Another division of the time data series by an analysis of the residuals. The change-point of the mean monthly discharge period determines the division of the time data series (Tab. 2, column $Q_{m}$ ).

\section{RESULTS}

\subsection{The analysis of the residuals}

The results of the analysis of the residuals showed change-points in 1941 for September and change-points in 1952 for November (Tab. 3). A considerable number of change-points were identified in the 1970s and 1980s. The range of colors from white to gray represents the period from the earliest change-point year to the latest change-point year.

Tab. 3 The change-points identified for the stations in discharges of the each month (Jan. - Dec.), summer season $\left(Q_{\text {sum }}\right)$, winter season $\left(Q_{\text {win }}\right)$ and mean monthly discharges $\left(Q_{m}\right)$

\begin{tabular}{|c|c|c|c|c|c|c|c|c|c|c|c|c|c|c|c|}
\hline Stat. & Jan & Feb & Mar & Apr & May & Jun & Jul & Aug & Sep & Oct & Nov & Dec & $\mathrm{Q}_{\text {sum }}$ & $\mathrm{Q}_{\text {win }}$ & $\mathrm{Q}_{\mathrm{m}}$ \\
\hline 5040 & 1974 & 1988 & 1948 & 1970 & 1987 & 1987 & 1952 & 1987 & 1941 & 1941 & 1952 & 1988 & 1942 & 1948 & 1948 \\
\hline 5311 & 1953 & 1977 & 1983 & 1972 & 1979 & 1989 & 1975 & 1972 & 1984 & 1980 & 1952 & 1966 & 1979 & 1983 & 1980 \\
\hline 5400 & 1947 & 1944 & 1953 & 1953 & 1974 & 2002 & 1985 & 1981 & 1975 & 1962 & 1952 & 1952 & 1964 & 1953 & 1981 \\
\hline 5880 & 1954 & 1954 & 1951 & 1956 & 1986 & 1954 & 1993 & 1978 & 1941 & 1981 & 1952 & 1962 & 1945 & 1983 & 1949 \\
\hline 6130 & 1974 & 1965 & 1951 & 1970 & 1972 & 1968 & 1966 & 1966 & 1941 & 1980 & 1952 & 1976 & 1966 & 1977 & 1967 \\
\hline 6200 & 1973 & 1965 & 1976 & 1970 & 1938 & 1954 & 1975 & 1986 & 1941 & 1981 & 1952 & 1989 & 1987 & 1964 & 2002 \\
\hline 7160 & 1953 & 1977 & 1981 & 1972 & 1996 & 1989 & 1966 & 1966 & 1941 & 1984 & 1952 & 1966 & 1985 & 1971 & 1981 \\
\hline 7290 & 1953 & 1977 & 1983 & 1970 & 1987 & 1989 & 1966 & 1966 & 1941 & 1984 & 1952 & 1980 & 1985 & 1981 & 1981 \\
\hline 7440 & 1982 & 1979 & 1970 & 1980 & 1942 & 1994 & 1952 & 1970 & 2009 & 1973 & 1952 & 1976 & 2009 & 1981 & 1981 \\
\hline 7820 & 2008 & 1979 & 1941 & 1961 & 1969 & 1964 & 1952 & 1970 & 1944 & 1963 & 1952 & 1976 & 1953 & 1983 & 1980 \\
\hline 8560 & 1953 & 1977 & 1945 & 1980 & 1945 & 1975 & 1960 & 1960 & 1941 & 1984 & 1952 & 1952 & 1955 & 1953 & 1955 \\
\hline 8870 & 1953 & 1965 & 1945 & 1980 & 1974 & 2004 & 1996 & 1985 & 1941 & 1973 & 1952 & 1985 & 1969 & 1983 & 1945 \\
\hline 9500 & 1953 & 1977 & 1986 & 1980 & 1973 & 1964 & 1996 & 1985 & 1941 & 1980 & 1980 & 1987 & 1969 & 1983 & 1981 \\
\hline 8320 & 1975 & 1969 & 1946 & 1970 & 1982 & 1967 & 1996 & 1960 & 1941 & 1973 & 1952 & 1950 & 1949 & 1971 & 1949 \\
\hline
\end{tabular}

Tab. 4 The change-points identified by Pettitt's test. The underlined years are change-points with a p-value $\leq 0.15$

\begin{tabular}{|c|c|c|c|c|c|c|c|c|c|c|c|c|c|c|c|}
\hline Stat. & Jan & Feb & Mar & Apr & May & Jun & Jul & Aug & Sep & Oct & Nov & Dec & $\mathrm{Q}_{\text {sum }}$ & $\mathbf{Q}_{\text {win }}$ & $\mathbf{Q}_{\mathrm{m}}$ \\
\hline 5040 & 1973 & 1988 & 1948 & 1988 & 1997 & 1987 & 1987 & 1987 & 1954 & 1954 & 1981 & 1998 & 1987 & 1948 & 1988 \\
\hline 5311 & $\underline{1953}$ & $\underline{1971}$ & $\underline{1983}$ & 1979 & 1996 & $\underline{1989}$ & $\underline{1975}$ & 1972 & $\underline{1980}$ & $\underline{1981}$ & $\underline{1952}$ & $\underline{1966}$ & $\underline{1980}$ & $\underline{1979}$ & $\underline{1980}$ \\
\hline 5880 & $\underline{1954}$ & $\underline{1954}$ & $\underline{1951}$ & $\underline{1952}$ & 1986 & 1954 & 1993 & 1978 & 1941 & 1981 & 1950 & $\underline{1962}$ & 1945 & 1983 & 1949 \\
\hline 5400 & 1947 & $\underline{1944}$ & 1944 & 1997 & 1974 & 2002 & 1985 & 1981 & 1941 & 1962 & $\underline{1952}$ & $\underline{1952}$ & 2002 & 1953 & 1981 \\
\hline 6130 & 1992 & 2006 & 1998 & 1972 & 1987 & $\underline{1968}$ & $\underline{1972}$ & $\underline{1986}$ & 1942 & $\underline{1966}$ & $\underline{1966}$ & 1976 & 1966 & $\underline{1977}$ & 1967 \\
\hline 7160 & 1983 & 1977 & 1983 & $\underline{1972}$ & 1996 & $\underline{1989}$ & 1975 & 1980 & 1981 & 1941 & $\underline{1952}$ & $\underline{1966}$ & $\underline{1980}$ & 1970 & $\underline{1980}$ \\
\hline 6200 & $\underline{1973}$ & 1965 & 2009 & 1970 & 1938 & 1957 & 1982 & $\underline{1986}$ & 1941 & 1941 & 1952 & 1989 & 1987 & 1936 & 2002 \\
\hline 7290 & 2000 & 1981 & 1983 & $\underline{1988}$ & $\underline{1987}$ & $\underline{1989}$ & 1972 & 1978 & 1981 & 1941 & $\underline{1952}$ & 1967 & $\underline{1985}$ & $\underline{1983}$ & $\underline{1985}$ \\
\hline 7440 & 1982 & $\underline{1981}$ & $\underline{1970}$ & 1988 & 1991 & 1991 & 1952 & 1952 & 1950 & 1962 & 1980 & $\underline{1970}$ & $\underline{1950}$ & 1980 & $\underline{1980}$ \\
\hline 7820 & 1983 & $\underline{1980}$ & 1941 & 1961 & 1964 & 1989 & 1975 & 1996 & 1980 & 1944 & 1945 & 1966 & 1950 & 1980 & 1980 \\
\hline 8560 & $\underline{1983}$ & $\underline{1973}$ & 1955 & 1980 & 1991 & 1976 & 1960 & 1960 & 1955 & 1945 & $\underline{1952}$ & $\underline{1968}$ & $\underline{1980}$ & 1970 & $\underline{1980}$ \\
\hline 8870 & 1953 & 2006 & 1986 & 2001 & 1969 & 1937 & 1996 & 1995 & 1941 & 1973 & 1945 & 1945 & 1969 & 1983 & 1945 \\
\hline 9500 & 2004 & 2006 & 1986 & 2000 & 1969 & 1964 & 1952 & 1981 & 1996 & 1945 & 1981 & 1982 & $\underline{1969}$ & 1983 & 1981 \\
\hline 8320 & 1961 & 1969 & 1971 & 1970 & 1936 & 1936 & 1996 & 1945 & 1941 & 1945 & $\underline{1952}$ & 1960 & $\underline{1949}$ & 1970 & 1949 \\
\hline
\end{tabular}




\subsection{Pettitt's test}

Pettitt's test showed similar results in its analysis of the residuals. The range of colors from white to gray represents the period from the earliest change-point year to the latest change-point year too. The underlined years in Tab. 4 are change-points with a p-value $\leq 0.15$. The change-points in September are not so significant, but November has six significant change-points in 1952. Overall, there were 8 changepoints in 1952. The entire measured period of the mean monthly discharges $\left(Q_{m}\right)$ has 4 statistically significant change-points out of a total of 9 change-points in 1980 .

More than a quarter of the change-points are statistically significant (58 change-points out of 210 with a p-value $\leq 0.15$ ), 51 changepoints with a $p$-value $\leq 0.10,35$ change-points with a $p$-value $\leq 0.05$, and 12 change-points with a $p$-value $\leq 0.01$.

The highest number of change-points from the 14 stage-discharge gauging stations were found at the Čierny Váh station (5311) with 12 change-points. Similar results for the location of the change-points were at the Banská Bystrica station (7160) and the Brehy station (7290). Both of them are on the Hron River.

\subsection{An analysis of the runoff regime changes by the deviations}

The analysis of the deviations compares two periods of the entire measurements for each month. The purpose of using four approaches is to analyze the differences that were visualized into the angles and then eventually into changes in the runoff regime.

The selected graph (Fig. 3) shows an analysis of the deviations for the stage-discharge gauging station 5040 (Moravský Sv. Ján) in August. The division of the measured period is based on the seasonal mean monthly discharges $\left(Q_{\text {sum }}\right.$ vs. $\left.Q_{\text {win }}\right)$. Specifically for this graph, the first period was from 1931 to 1942 and the second period from 1943 to 2016. The change-point was in 1942 (see Tab. 2, row 5040, column $\left.Q_{\text {sum }}\right)$. The angle between the trend lines is $21.1^{\circ}$. This means a significant change in the runoff regime in August.

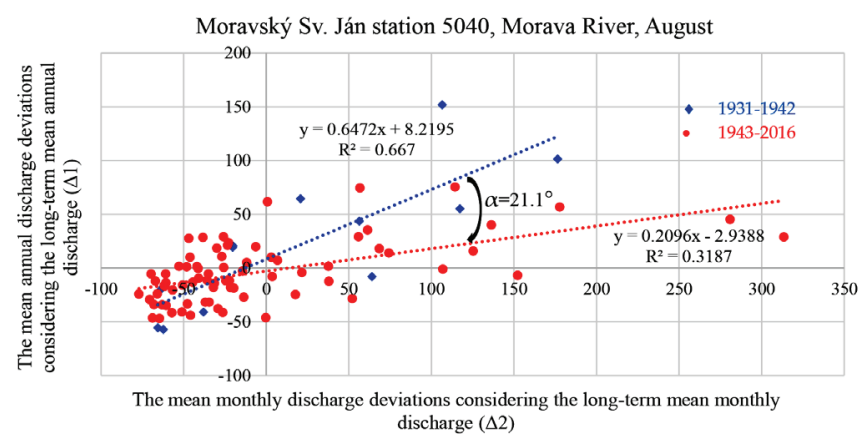

Fig. 3 The analysis of the deviations of the Moravsky Sv. Ján station 5040, Morava River in August

Using the four different methods for all the months at each station, angles were selected that ranged from $\left(10^{\circ},-10^{\circ}\right)$ to $\left(20^{\circ},-20^{\circ}\right)$; in Tab. A1, the underlined values and then the angles greater than the interval $\left(20^{\circ},-20^{\circ}\right)$, and in Tab. A1, the double underlined values can be seen. A significant number of changes in the runoff regime were identified at the Moravský Sv. Ján station (5040), where from May to November, but excluding September, changes in the runoff regime were identified. The Dierová (5880), Mratin (6130), Brehy (7290) and Hanušovce (9500) stations are without change in the runoff regime. The method found the most changes in the runoff regime were in October (Fig. 4 to 8), where changes in five stations were identified for division by seasonal mean monthly discharges $\left(Q_{\text {sum }}\right)$. The methods of division by change-point from $Q_{\text {sum }}, Q_{\text {win }}$ and $Q_{m}$ show bigger changes in the size of the angle $\alpha$ than division by change-point from 30-year period and 2 halves.

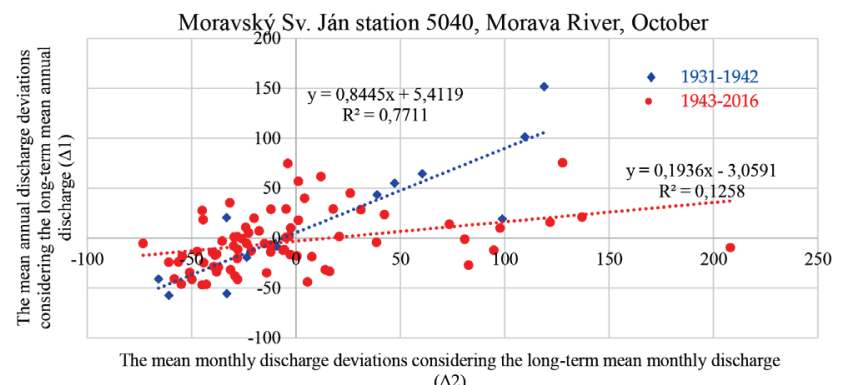

Fig. 4 The analysis of the deviations of the Moravsky Sv. Ján station 5040, Morava River in October with angle $\alpha=29.2^{\circ}$.

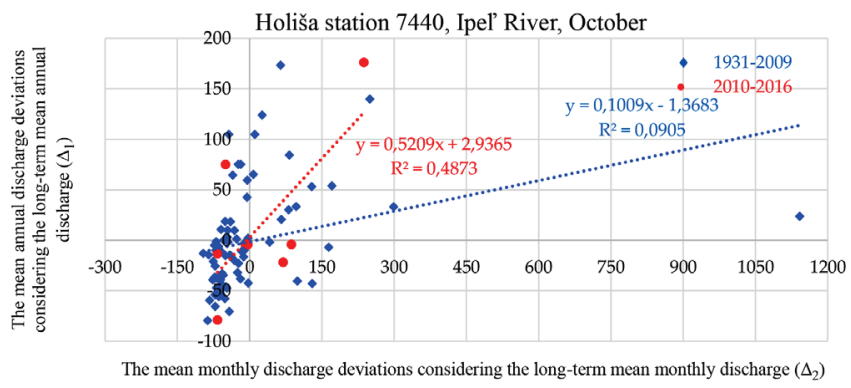

Fig. 5 The analysis of the deviations of the Holiša station 7440, Ipel' River, in October with angle $\alpha=-21.8^{\circ}$.

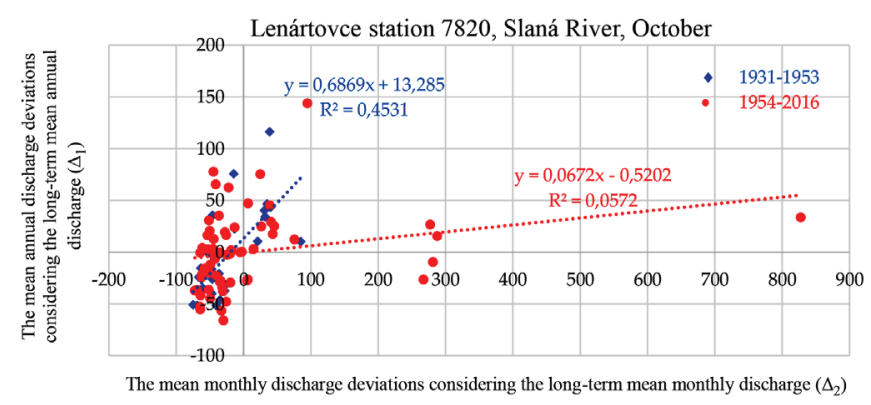

Fig. 6 The analysis of the deviations of the Lenártovce station 7820 , Slaná River, in October with angle $\alpha=\underline{\underline{30.6^{\circ}}}$.

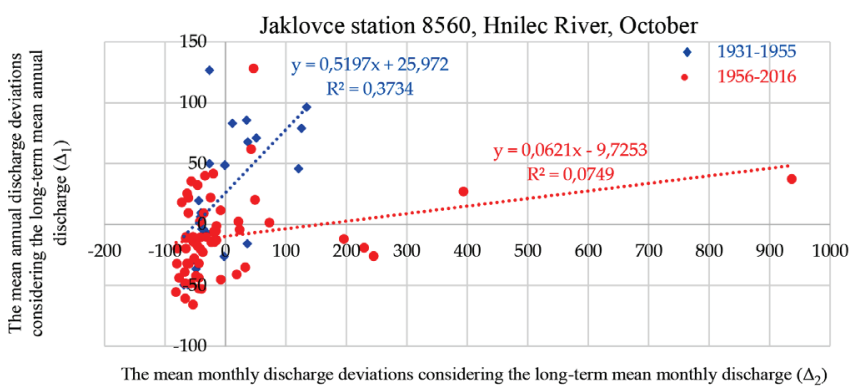

Fig. 7 The analysis of the deviations of the Jaklovce station 8560 Hnilec River, in October with angle $\alpha=23.9^{\circ}$ 


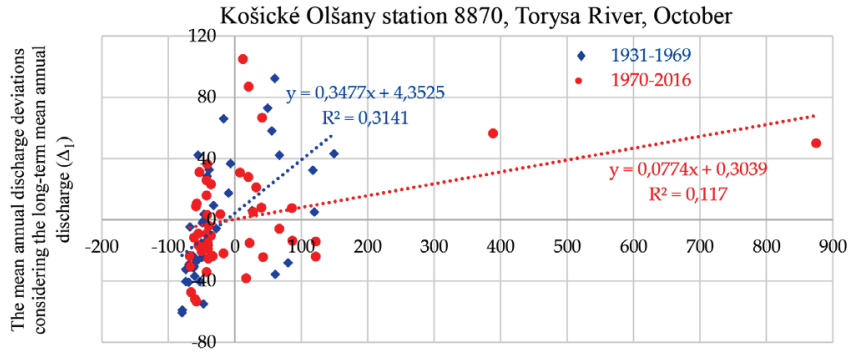

The mean monthly discharge deviations considering the long-term mean monthly discharge $\left(\Delta_{2}\right)$

Fig. 8 The analysis of the deviations of the Košické Olšany station 8870, Torysa River, in October with angle $\alpha=14.7^{\circ}$.

\section{CONCLUSIONS}

The analysis of the residuals identified the most changes in September (the year 1941) and in November (the year 1952). A lot of the change-points were identified in the 1970s and 1980s. This simple method is applicable to hydrological data series. A disadvantage is the absence of statistical significance, but Pettitt's test, which showed statistical significance, was used in the study.

The change-points identified by Pettitt's test show several significant change-points in November of 1952. Approximately a quarter of the change-points were statistically significant, i.e., 51 change-points with a $p$-value $\leq 0.10,35$ change-points with a p-value $\leq 0.05$, and 12 change-points with a $p$-value $\leq 0.01$.
The highest number of change-points from the 14 stage-discharge gauging stations belonged to the Čierny Váh station (5311) with 12 change-points. Similar results for the location of the change-points were at the Banská Bystrica station (7160) and the Brehy station (7290). Both of them are on the Hron River.

A considerable number of changes in the runoff regime were identified at the Moravský Sv. Ján (5040) station. The method found the most changes in the runoff regime were in October, five stations were identified for division by seasonal mean monthly discharges $\left(Q_{\text {sum }}\right)$. The Dierová (5880), Mratin (6130), Brehy (7290) and Hanušovce (9500) stations are without change in the runoff regime. The methods of division by change-point from $Q_{\text {sum }}, Q_{\text {win }}$ and $Q_{m}$ show bigger changes in the size of the angle $\alpha$ than division by changepoint from 30-year period and 2 halves.

The results of the analyses show certain changes in the mean monthly discharges, but in order to confirm their correctness, it will be necessary to examine other hydrological and meteorological elements and use other methods for identifying the changes. Studies directed at changes in hydrological regimes are of great importance, especially in the fields of water resources management, flood protection, and the revitalization of rivers.

\section{Acknowledgments}

This work was supported by the Science Grant Agency (Slovakia) under Contract No. VEGA 1/0891/17 and APVV-15-0496.

\section{Appendix A}

Tab. A1 The angles $\alpha$ identified by the four different methods

\begin{tabular}{|c|c|c|c|c|c|c|c|c|c|c|c|c|c|}
\hline \multicolumn{2}{|c|}{ St. Angles $\alpha$} & Jan & Feb & Mar & Apr & May & Jun & Jul & Aug & Sep & Oct & Nov & Dec \\
\hline \multirow{4}{*}{ 움 } & 30-year per. & 5.6 & -0.2 & 4.7 & 8.4 & 7.9 & $\underline{13.7}$ & 8.0 & 5.8 & -5.7 & $\underline{19.3}$ & 9.6 & -5.4 \\
\hline & 2 halves & 8.4 & 1.8 & 4.2 & 7.2 & 2.0 & 1.0 & $\underline{11.2}$ & 4.2 & -6.0 & $\underline{\underline{20.2}}$ & 7.2 & 8.5 \\
\hline & CH-P-Qsum/Qwin & 2.8 & 4.3 & 0.2 & 8.7 & $\underline{13.7}$ & $\underline{18.4}$ & $\underline{\underline{36.0}}$ & $\underline{\underline{21.1}}$ & -8.3 & $\underline{29.2}$ & $\underline{13.1}$ & 7.1 \\
\hline & CH-P of Qm & 2.8 & 4.3 & 0.2 & 8.7 & $\underline{11.6}$ & $\underline{15.1}$ & $\underline{\underline{26.6}}$ & $\underline{18.3}$ & -9.2 & $\underline{\underline{24.9}}$ & $\underline{13.1}$ & 7.1 \\
\hline \multirow{4}{*}{$\vec{n}$} & 30-year per. & -1.2 & 2.8 & -3.5 & 3.5 & -1.5 & 4.1 & 0.0 & 6.1 & 1.5 & 6.8 & -5.6 & -11.2 \\
\hline & 2 halves & -1.9 & 0.0 & 2.6 & 5.5 & 2.0 & 2.2 & 1.8 & 8.0 & 4.6 & 1.7 & -5.7 & -9.3 \\
\hline & CH-P-Qsum/Qwin & -4.5 & -1.2 & -5.5 & 2.1 & -0.6 & 2.4 & -0.3 & 7.4 & 2.9 & -5.0 & -5.5 & $\underline{-10.5}$ \\
\hline & $\mathrm{CH}-\mathrm{P}$ of Qm & -1.9 & -0.4 & 0.2 & 2.8 & -1.2 & 7.3 & 0.2 & 7.3 & 3.2 & -7.9 & -5.8 & $\underline{-10.0}$ \\
\hline \multirow{4}{*}{$\begin{array}{l}8 \\
\text { ơ } \\
\text { in }\end{array}$} & 30-year per. & 3.9 & -1.7 & -7.5 & 9.6 & 3.0 & -0.9 & 2.2 & 3.9 & -2.8 & -5.5 & 0.1 & -4.9 \\
\hline & 2 halves & 2.9 & -3.2 & -8.6 & 6.7 & 6.5 & -5.5 & 2.8 & 2.5 & -2.6 & -8.0 & -2.0 & -3.0 \\
\hline & CH-P-Qsum/Qwin & -0.8 & -5.7 & -8.5 & $\underline{10.3}$ & 6.0 & 0.3 & 2.7 & 1.5 & -2.5 & -7.7 & 0.7 & -1.5 \\
\hline & $\mathrm{CH}-\mathrm{P}$ of Qm & 6.0 & -1.3 & -7.9 & 5.1 & 2.2 & -1.2 & 5.3 & 7.6 & -0.9 & -4.9 & -3.4 & -10.1 \\
\hline \multirow{4}{*}{$\begin{array}{l}\infty \\
\infty \\
\infty \\
\text { in }\end{array}$} & 30-year per. & -3.0 & 4.6 & -1.1 & -2.4 & -3.6 & 0.7 & 0.6 & -2.4 & -2.2 & -4.7 & 0.5 & -0.1 \\
\hline & 2 halves & -0.9 & 3.2 & 0.0 & 0.0 & 0.4 & -1.6 & 1.1 & -1.1 & -1.5 & -2.5 & -5.8 & -7.2 \\
\hline & CH-P-Qsum/Qwin & -7.2 & 5.1 & -3.4 & -3.4 & -1.1 & -8.5 & -6.1 & -1.0 & -2.5 & -1.2 & -0.5 & -6.0 \\
\hline & $\mathrm{CH}-\mathrm{P}$ of Qm & 0.5 & 0.1 & -6.5 & 0.0 & -0.9 & -3.7 & 5.1 & 0.6 & -3.5 & -1.4 & 0.4 & 0.5 \\
\hline \multirow{4}{*}{ 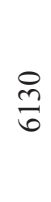 } & 30-year per. & -5.9 & -1.2 & 5.1 & 6.9 & -2.0 & -5.9 & -1.7 & 2.1 & 4.0 & 3.2 & 1.8 & -7.5 \\
\hline & 2 halves & -0.8 & -0.4 & 4.8 & 5.7 & 2.8 & -6.7 & -0.8 & 1.2 & 4.1 & 5.1 & -4.4 & 0.1 \\
\hline & CH-P-Qsum/Qwin & -2.7 & -0.1 & 7.0 & 4.2 & 2.7 & -6.9 & -0.2 & 1.9 & 4.5 & 5.7 & 2.8 & -6.2 \\
\hline & $\mathrm{CH}-\mathrm{P}$ of Qm & -0.8 & -0.4 & 4.8 & 5.7 & 2.8 & -6.7 & -0.8 & 1.2 & 4.1 & 5.1 & -4.4 & 0.1 \\
\hline
\end{tabular}




\begin{tabular}{|c|c|c|c|c|c|c|c|c|c|c|c|c|c|}
\hline \multicolumn{2}{|c|}{ St. Angles $\alpha$} & \multirow{2}{*}{$\begin{array}{l}\text { Jan } \\
\underline{11.7} \\
\end{array}$} & \multirow{2}{*}{$\frac{\text { Feb }}{-0.6}$} & \multirow{2}{*}{$\begin{array}{c}\text { Mar } \\
2.0 \\
\end{array}$} & \multirow{2}{*}{$\begin{array}{c}\text { Apr } \\
2.0 \\
\end{array}$} & \multirow{2}{*}{$\begin{array}{c}\text { May } \\
0.2 \\
\end{array}$} & \multirow{2}{*}{$\begin{array}{c}\text { Jun } \\
-3.2 \\
\end{array}$} & \multirow{2}{*}{$\begin{array}{r}\text { Jul } \\
-1.3\end{array}$} & \multirow{2}{*}{$\begin{array}{c}\text { Aug } \\
8.3 \\
\end{array}$} & \multirow{2}{*}{$\frac{\text { Sep }}{4.3}$} & \multirow{2}{*}{$\begin{array}{c}\text { Oct } \\
4.6 \\
\end{array}$} & \multirow{2}{*}{$\begin{array}{c}\text { Nov } \\
-0.3 \\
\end{array}$} & \multirow{2}{*}{$\frac{\text { Dec }}{-0.2}$} \\
\hline & 30-year per. & & & & & & & & & & & & \\
\hline \multirow{3}{*}{ ஓ } & 2 halves & 6.9 & 0.6 & 3.6 & 4.3 & 0.4 & -3.0 & 0.3 & 5.1 & 1.9 & 3.3 & -2.3 & -1.7 \\
\hline & CH-P-Qsum/Qwin & 6.0 & -1.9 & 2.1 & 2.8 & 1.5 & -5.6 & -0.2 & 4.3 & -0.4 & 4.3 & -1.7 & 0.8 \\
\hline & CH-P of Qm & $\underline{12.4}$ & 5.5 & -0.8 & 4.9 & 0.1 & -3.6 & 8.8 & -3.1 & -5.6 & 3.4 & -5.6 & -5.5 \\
\hline \multirow{4}{*}{$\underset{8}{\stackrel{8}{1}}$} & 30 -year per. & -4.0 & 4.8 & 2.3 & $\underline{10.3}$ & 1.9 & 3.9 & -2.9 & 9.7 & 2.4 & $\underline{14.1}$ & 3.2 & -0.5 \\
\hline & 2 halves & 0.0 & -1.8 & 6.4 & 9.0 & 3.8 & 3.2 & 2.0 & 9.5 & 4.4 & 7.7 & 2.0 & 2.2 \\
\hline & CH-P-Qsum/Qwin & -1.6 & -2.4 & 4.4 & 6.4 & $\underline{-12.4}$ & -0.6 & 0.9 & $\underline{10.6}$ & 2.8 & -5.8 & 0.5 & 0.6 \\
\hline & CH-P of Qm & -2.5 & 0.5 & 3.7 & 7.8 & $\underline{-10.1}$ & 0.6 & -0.2 & $\underline{10.4}$ & 4.4 & -4.8 & 2.5 & -0.9 \\
\hline \multirow{4}{*}{ ৯े } & 30-year per. & -8.4 & 2.4 & 4.5 & 4.9 & -2.6 & -1.5 & -0.9 & 8.2 & 0.5 & $\underline{14.1}$ & 1.5 & -0.2 \\
\hline & 2 halves & -3.3 & -0.8 & 8.4 & 3.2 & 3.2 & 0.5 & 3.4 & 7.1 & 2.7 & 3.1 & -0.1 & 4.2 \\
\hline & CH-P-Qsum/Qwin & -4.1 & -1.1 & 6.5 & 0.9 & -8.9 & -4.7 & 1.8 & 7.3 & 0.0 & -6.5 & -1.8 & 2.6 \\
\hline & CH-P of Qm & -4.6 & -0.8 & 4.3 & 2.7 & -1.0 & -3.6 & 1.3 & 7.7 & 2.4 & -5.7 & 1.7 & -0.8 \\
\hline \multirow{4}{*}{$\underset{⿱}{\stackrel{+}{7}}$} & 30-year per. & $\underline{-11.9}$ & -5.5 & -5.6 & $\underline{11.0}$ & -5.1 & $\underline{10.3}$ & $\underline{-13.6}$ & -1.2 & 1.9 & 5.6 & -5.9 & -5.9 \\
\hline & 2 halves & -9.8 & -2.7 & -2.1 & 5.9 & 1.1 & 6.8 & -9.1 & 0.3 & 3.8 & 21.5 & -2.9 & 3.6 \\
\hline & CH-P-Qsum/Qwin & -8.4 & -9.2 & -2.6 & 6.0 & -8.7 & -8.1 & -8.0 & $\underline{\underline{-22.9}}$ & 7.4 & $\underline{-21.8}$ & -6.5 & -8.6 \\
\hline & CH-P of Qm & -8.6 & -9.1 & -3.5 & 5.9 & -5.5 & 5.0 & -10.0 & 0.0 & 3.6 & $\underline{-15.1}$ & -6.6 & -8.6 \\
\hline \multirow{4}{*}{$\underset{\infty}{\infty}$} & 30-year per. & $\underline{-12.6}$ & 4.8 & -2.7 & 9.7 & -8.2 & 6.6 & -10.0 & 0.4 & -3.2 & $\underline{\underline{22.5}}$ & -3.7 & -6.2 \\
\hline & 2 halves & $\underline{-10.6}$ & 2.7 & 0.2 & 2.8 & -2.5 & 4.5 & -6.6 & 1.1 & 2.4 & $\underline{10.7}$ & -2.0 & 4.1 \\
\hline & CH-P-Qsum/Qwin & -10.5 & -3.4 & -0.2 & 1.0 & 3.8 & $\underline{11.1}$ & 8.6 & $\underline{18.4}$ & -3.0 & $\underline{\underline{30.6}}$ & -4.6 & -8.4 \\
\hline & CH-P of Qm & -10.5 & -3.4 & -0.2 & 1.0 & -10.4 & 2.6 & -9.2 & 2.4 & 1.6 & -4.1 & -4.6 & -8.4 \\
\hline \multirow{4}{*}{$\begin{array}{l}8 \\
i \\
\infty\end{array}$} & 30-year per. & -7.0 & $\underline{12.2}$ & -5.2 & 9.4 & -7.0 & 0.0 & -9.5 & -5.1 & 3.1 & $\underline{21.5}$ & -8.6 & -6.8 \\
\hline & 2 halves & -6.0 & $\underline{10.5}$ & 0.9 & 7.1 & -2.1 & -0.1 & -3.7 & -2.0 & 5.3 & $\underline{14.2}$ & -4.1 & 4.2 \\
\hline & CH-P-Qsum/Qwin & -2.4 & $\underline{12.6}$ & -2.4 & 9.7 & -4.6 & 1.8 & -0.8 & 7.6 & -0.6 & $\underline{\underline{23.9}}$ & -3.6 & 0.4 \\
\hline & CH-P of Qm & -2.4 & $\underline{12.6}$ & -2.4 & 9.7 & -4.3 & -0.6 & -1.5 & -4.5 & 1.0 & $\underline{\underline{24.7}}$ & -3.6 & 0.4 \\
\hline \multirow{4}{*}{$\underset{\infty}{\infty}$} & 30 -year per. & -1.0 & 6.1 & 2.4 & 3.9 & 8.6 & 1.0 & 4.1 & -1.2 & 0.4 & $\underline{11.0}$ & -2.3 & -5.8 \\
\hline & 2 halves & 0.6 & 1.8 & 3.7 & -0.3 & $\underline{10.7}$ & 1.1 & 3.2 & 0.6 & -1.5 & $\underline{15.0}$ & -4.3 & -0.2 \\
\hline & CH-P-Qsum/Qwin & 2.1 & 2.1 & -2.2 & -1.8 & $\underline{11.2}$ & 0.6 & 6.1 & 1.9 & 0.3 & $\underline{14.7}$ & -6.3 & -8.8 \\
\hline & CH-P of Qm & $\underline{11.8}$ & $\underline{12.1}$ & 1.7 & -0.2 & 8.7 & 8.7 & 5.4 & $\underline{15.6}$ & -5.2 & $\underline{11.0}$ & -4.5 & 6.2 \\
\hline \multirow{4}{*}{ 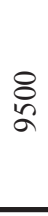 } & 30 -year per. & 3.2 & 8.6 & -1.0 & -0.9 & 3.4 & -0.8 & 3.2 & -3.3 & -1.6 & $\underline{10.8}$ & 0.3 & -5.4 \\
\hline & 2 halves & 1.5 & 1.8 & 3.6 & -1.0 & 6.3 & -0.7 & 1.1 & -2.8 & -4.6 & 9.0 & -8.4 & -0.7 \\
\hline & CH-P-Qsum/Qwin & 5.1 & 7.0 & -5.6 & -5.8 & 5.0 & -1.8 & 1.6 & -2.9 & -4.3 & 8.2 & -2.0 & -2.8 \\
\hline & CH-P of Qm & 5.1 & 7.0 & -5.6 & -5.8 & 5.7 & 2.3 & 5.3 & 1.7 & 0.9 & 1.1 & -2.0 & -2.8 \\
\hline \multirow{4}{*}{$\underset{\infty}{\stackrel{\infty}{~}}$} & 30 -year per. & 5.2 & 2.4 & 8.8 & 5.1 & 5.6 & 3.4 & 2.6 & 2.0 & 1.2 & 1.7 & 2.8 & -6.4 \\
\hline & 2 halves & 3.5 & -1.3 & $\underline{13.9}$ & 5.6 & 8.0 & 0.9 & 3.0 & 2.8 & 1.8 & 3.4 & 2.1 & -0.7 \\
\hline & CH-P-Qsum/Qwin & 6.2 & -1.7 & $\underline{13.3}$ & 4.1 & 5.9 & 0.2 & -0.6 & 8.8 & -3.5 & 3.6 & 0.7 & -1.6 \\
\hline & CH-P of Qm & $\underline{10.1}$ & $\underline{11.8}$ & 5.7 & $\underline{11.6}$ & 5.9 & 0.2 & -0.6 & 8.8 & -3.5 & 3.6 & 4.4 & 4.3 \\
\hline
\end{tabular}




\section{REFERENCES}

Barnett, T. P. - Adam, J. C. - Lettenmaier, D. P. (2005) Potential Impacts of a Warming Climate on Water Availability in Snow-Dominated Regions. In: Nature, Dec. 2005 DOI: 438. 3039. 10.1038/nature04141.

Gao, P. - Zhang, X. C. - Mu, X.-M. - Wang, F. - Li, R. - Zhang, X. (2010) Trend and change-point analyses of streamflow and sediment discharge in the Yellow River during 1950-2005. Hydrol. Sci. J. 55(2), 2010, pp. $275-285$.

Gallagher, C. - Lund, R. - Robbins, M. (2013). Change-point Detection in Climate Time Series with Long-Term Trends. J. Climate, 26, 2013, pp. 4994-5006, https://doi.org/10.1175/JCLI-D-12-00704.1.

Guo, L.P. - Yu, Q. - Gao, P. - Nie, X. F. - Liao, K. T. - Chen, X. L. Hu, J. M. - Mu, X. M. (2018) Trend and Change-Point Analysis of Streamflow and Sediment Discharge of the Gongshui River in China during the Last 60 Years. Water 2018, 10, 1273.

Hlavčová, K. - Szolgay, J. - Kohnová, S. - Hlásny, T. (2008) Simulation of hydrological response to the future climate in the Hron River basin. Journal of Hydrology and Hydromechanics, 56. 2008; pp. 163-175.

Implementation of Directive 2007/60/EC of the European Parliament and of the Council of 23 Oct. 2007 on the assessment and management of flood risks, The preliminary flood risk assessment in the Bodrog sub-basin. Ministry of the Environment of the Slovak Republic, Dec. 2011, pp. 38 - 42. Available online: http:// www.minzp.sk/sekcie/temyoblasti/voda/ochrana-pred-povodnami/manazment-povodnovych-rizik/ (accessed on 28. Oct. 2018).

Jeneiová, K. - Kohnová, S. - Hall, J. - Parajka, J. (2016) Variability of seasonal floods in the Upper Danube River baisn. In J. Hydrol. Hydromech. 64, 2016, 4, pp 357-366. DOI: 10.1515/johh-20160037.

Lee, S. - Kim, S. U. (2016) Comparison between change point detection methods with synthetic rainfall data and application in South Korea. KSCE Journal of Civil Engineering, May 2016, Vol. 20, pp. 1558 - 1571 https://doi.org/10.1007/s12205-014-0228-5.
Pettitt, A.N. (1979) A non-parametric approach to the change-point problem. J Appl Stat 28(2): pp. 126 - 135

Reeves, J. - Chen, J. - Wang, X. L. - Lund, R. - Lu, Q. Q. (2007) A Review and Comparison of Changepoint Detection Techniques for Climate Data. J. Appl. Meteor. Climatol. 46, 2007, pp. 900 915, https://doi.org/10.1175/JAM2493.1.

Sagarika, S. - Kalra, A. - Ahmad, S. (2014) Evaluating the effect of persistence on long-term trends and analyzing step changes in streamflows of the continental United States. In: Journal of Hydrology 517, pp. $36-53$.

Škvarenina, J. - Szolgay, J. - Šiška, B. - Lapin, M. (eds.) (2010) The climate change and landscape - Impacts of the climate change and assessment of the territorial vulnerability in Slovakia in water resources management, forests and agriculture. Study XXV, Vol. XXII, the Slovak Bioclimatological Society, Zvolen, 2010, ISBN 978-80-228-2272-5.

Tegelhoffová, M. - Danáčová, M. - Szolgay, J. (2013) A spatial assessment of the indicator of hydrological regime changes. In ACTA HYDROLOGICA SLOVACA, Vol. 14, No. 1, 2013, pp. $243-251$

Villarini, G. - Smith, J. A. - Serinaldi, F. - Ntelekos, A. A. (2011) Analyses of seasonal and annual maximum daily discharge records for central Europe. Journal of Hydrology, Volume 399, Issues 3-4, pp. 299-312, ISSN 0022-1694, https://doi.org/10.1016/j. jhydrol.2011.01.007.

Xiong, L. - Guo, S. (2004) Trend Test and Change-Point Detection for the Annual Discharge Series of the Yangtze River at the Yichang Hydrological Station. Hydrological Sciences Journal/ Journal des Sciences Hydrologiques. 2004, 49. 99-112. 10.1623/ hysj.49.1.99.53998

Xue, Z. G. - Gochis, D. J. - Yu, W. - Keim, B. D. - Rohli, R. V. Zang, Z. - Sampson, K. - Dugger, A. - Sathiaraj, D. - Ge, Q. (2018) Modeling Hydroclimatic Change in Southwest Louisiana Rivers. Water 2018, 10, 596. 